\title{
Mario Magallón Anaya, La Democracia en América Latina, México, CCyDEL-UnAm/Plaza y Valdés, 2003, 427 pp.
}

Esta obra consta de una introducción, nueve capítulos, conclusiones y bibliografía y en ella, según el propio autor: se aborda de forma muy general, el doloroso contexto histórico de los gobiernos autoritarios y militares latinoamericanos. Sin embargo, las reflexiones del doctor Magallón Anaya nos llevan más allá de ese ámbito.

La década de los ochenta se conoció en América Latina como La década perdida durante la cual se iniciaron los procesos de transición a la democracia; sin embargo, en las últimas dos décadas del siglo XX los gobiernos de América Latina se caracterizaron por ser: populistas, desarrollistas, militares, de autoritarismo burocrático y de democracias autoritarias, como lo fue el caso concreto de Chile con Augusto Pinochet.

De acuerdo con el autor, la democracia latinoamericana en los últimos 20 años se ha definido por ser limitada, defectiva e incompleta, lo que ha diluido y confundido el propio concepto, así como sus procesos. De hecho, la aplicación del modelo neoliberal, la "transición democrática" y su ejercicio se presentaron como aspectos contrarios y contradictorios, ya que en el transcurrir del siglo pasado se va a presentar un deslizamiento de los gobiernos democráticos liberales excluyentes a los oligárquicos, a las tiranías, a la contrarrevolución, a los golpes de Estado, a las dictaduras civiles y militares, al autoritarismo y a las transiciones democráticas.

El punto focal es que en América Latina este tipo de régimen tiene grandes limitaciones y alcances, como también problemas que requieren ser resueltos, como el hecho de que es algo "procesual", algo que se va construyendo día a día, y es a partir de una filosofía de la praxis que se analiza lo social y lo político de nuestra América.

La filosofía latinoamericana, de hecho, toma conciencia de un mundo opresor que busca limitar la radicalidad y crítica de la filosofía como actividad libre, racional y responsable. La hipótesis que se maneja en esta obra corre en el sentido de que en América Latina los análisis 
políticos, sociales y económicos no son reflejo de los estudios, del mismo carácter, que el de los europeos o estadounidenses, sino el resultado de una relación dialéctica entre el realismo económico-político de la globalidad, generada y regida por los países posindustriales del mundo... donde se confirman sus relaciones de dependencia y de interdependencia.

Aunque en América Latina muy pocos países han disfrutado de democracias plenas o de cuasidemocracias, como les denomina muy acertadamente el abogado constitucionalista guatemalteco Jorge Mario García Laguardia, se han dado casos de este proceso de transición como en Costa Rica, que alcanzó y ha mantenido su democracia. Sin embargo, la representación de ésta ha cambiado desde el siglo XVIII cuando se le definía como la soberanía del pueblo y la destitución del antiguo régimen fundado en la herencia, el derecho divino y los privilegios, confundiéndose con el concepto de nación, como aconteció en los casos de Estados Unidos y Francia.

Ya de hecho, durante el siglo XIX, el temor a una dictadura nacional revolucionaria reemplazó la idea de soberanía popular por el concepto de un poder que estuviera al servicio de los intereses de la clase más numerosa y, de esta forma, la idea de nación quedó sustituida por la de pueblo, lo que permitió a la democracia hacerse más representativa; de hecho, desde Benjamín Constant hasta Norberto Bobbio, ésta ha venido a ser un criterio central de la libertad del hombre moderno.

A su vez, la política democrática asoció el concepto de modernidad e incluso el de racionalización con los intereses de los trabajadores. Habrá que recordar que Lenin llegó a hablar de una alianza del soviet y de la electrificación. Pero cuando se rompe el equilibrio entre lo universal y lo particular y entre la razón y el pueblo, la imagen de la democracia se hace más defensiva y su concepto, que en un principio se había venido identificando primero con el de sociedad, se fue acercando progresivamente al sujeto, del cual tiende a ser su expresión política.

El autor nos deja ver muy claramente que la historia de la democracia es la historia de la progresiva separación de dos principios fundamentales: la soberanía popular y los derechos del hombre. Aunque la 
idea de soberanía, que nos conduce al poder popular, hace caso omiso de la legalidad porque se encuentra permeada de aspiraciones revolucionarias, es decir, que la noción de los derechos del hombre queda reducida a la defensa de la propiedad, lo que conduce a pensar que la democracia es vigorosa sólo cuando se somete al poder político, al respeto por derechos definidos cada vez más ampliamente como derechos cívicos, primero, y luego sociales e incluso culturales.

Al pasar de la idea unificadora de soberanía popular a la defensa de los derechos, la democracia se impone la obligación de combatir en dos frentes y ya no en uno solo. Por un lado, tiene que combatir el poder absoluto, el despotismo militar y el partido totalitario y, por otro, tiene que limitar el individualismo extremo, los juegos corruptores así como el poder invasor de administraciones y empresas.

La democracia existirá siempre y cuando se combine la integración, es decir, la ciudadanía; cuando se respeten las identidades, las necesidades y los derechos. Ésta estará ausente sin la combinación de una sociedad abierta y el respeto por los actores sociales, lo que nos aleja de su concepción popular y liberal. Por otro lado, sólo podrá haber actores sociales si se vinculan la conciencia interiorizada de derechos personales y colectivos, el reconocimiento de la pluralidad de los intereses y las ideas (dominadores y dominados) y la responsabilidad de cada uno respecto de orientaciones culturales comunes lo que podría traducirse como el orden de las instituciones políticas.

Isaiah Berlin y Karl Popper definen y defienden la democracia como el régimen que impide a cualquiera adueñarse del poder o conservarlo contra la voluntad de la mayoría; de hecho, el pensamiento liberal ha reemplazado al movimiento revolucionario como su defensor. En Europa, por ejemplo, el derrumbe de ciertos regímenes tuvo como consecuencia la sustitución de una economía administrada por una economía de mercado, por lo que la democracia se define menos como el régimen que asegura la libre representación de los intereses.

La palabra "democracia" está tan manoseada que vacilamos en emplearla. Claude Lefort la define, no por el poder del pueblo sino por la 
ausencia de poder central. ¿No entraña un riesgo de perversión y no sólo resulta más claro y seguro hablar tan solo de libertades y desconfiar de todas las concepciones del poder? Este vuelco del concepto de democracia constituye un punto de partida de la reflexión. No puede haber libertad política si el poder no se encuentra limitado por un principio superior a él, un principio que se opone a que el poder llegue a ser absoluto.

De aquí que la democracia carece de fundamento si las desigualdades sociales son tales que los habitantes ya no tienen el sentimiento de un bien común. Rousseau solía decir que para que ésta sea vigorosa es necesario que exista cierta igualdad de las condiciones y una conciencia nacional, porque la conciencia de la ciudadanía, según nos ha mostrado T. H. Marshall, es lo único que permite restablecer la unidad de la sociedad, quebrantada por los conflictos y la distancia entre las clases sociales.

En el caso concreto de Estados Unidos, una sociedad democrática descansa necesariamente en valores comunes y especialmente en valores religiosos y morales, cuya presencia asegura la limitación del poder político; por ello la exaltación de la sociedad nacional acarrea más peligros que apoyos a la democracia.

De hecho, Norberto Bobbio relaciona la democracia con el control de la violencia, ya que ésta no puede existir si no es "representativa" porque la democracia supone una sociedad civil vigorosamente estructurada, asociada a una sociedad política integrada e independiente del Estado.

Por otro lado, estamos acostumbrados a pensar que los partidos políticos son instrumentos indispensables del gran conjunto de demandas sociales y de las decisiones políticas generales, aunque el espacio de los partidos políticos es sumamente estrecho, hay una multiplicación de los lobbies y el aplastamiento de las demandas sociales por la acción de los ideólogos y los aparatos políticos. Cuanto más un partido político se considera portador de un modelo de sociedad, en lugar de ser un simple instrumento de formación de decisiones políticas, más se debilita la democracia y más subordinados están los ciudadanos a los dirigentes de los partidos. Esta debilidad es fácilmente observada en 
Francia y España así como en la mayoría de los países de América Latina; Albert Hirschman comenta al respecto que los "grandes partidos populares" se acercan, a veces peligrosamente, a partidos únicos.

Durante el siglo XX la democracia obtuvo algunas victorias y ni siquiera libró muchas batallas: Solidaridad en Polonia (1980-1981), los estudiantes chinos en 1989 y la caída del Muro de Berlín. En América Latina por su parte, las dictaduras militares accedieron a entregar el poder a las autoridades civiles: Brasil, Uruguay, Chile y Paraguay. En el caso concreto de Argentina, fue la derrota militar y no una sublevación popular, lo que condujo al poder a un régimen democrático. Irónicamente, la euforia casi siempre va acompañada por una extraña ausencia de reflexión; los intelectuales no desempeñan ningún papel importante en este establecimiento de las nuevas democracias, mientras que antes habían ocupado el primer lugar en las luchas contra las dictaduras.

Seymur Martin Lipset aduce que la democracia está tan estrechamente relacionada con la abundancia que puede definirse como la dimensión política de la modernización, porque ésta es identificada con la sociedad liberal, con una sociedad de desarrollo endógeno en la que la acción modernizadora se confunde con el ejercicio de la modernidad misma.

Marcel Gauchet y Michel Foucault marcan claramente que mientras más abiertas e igualitarias son nuestras sociedades, más se acentúa en ellas la marginación y aun la exclusión de aquellos que se ajustan a normas sociales o culturales diferentes de las del mainstream o que acumulan desventajas personales y colectivas. Pero, jeste esquema no puede aplicarse a Europa por su larga trayectoria socialdemócrata! En América Latina, la degradación de los regímenes nacionales y populares acarrearon primero, en numerosos países, el triunfo de dictaduras militares y el reemplazo del proteccionismo por una política liberal que buscaba ventajas comparativas en el mercado mundial; esta política económica, si bien aceptó las elecciones libres, no hizo que por eso se invirtiera la tendencia: los pobres se han hecho más pobres, la clase media deteriorada y los ricos conservan sus posiciones. Esto, definitivamente, ;marca los límites de la democratización! 
Robert K. Menton afirma que puede considerarse democracia y democrática en la medida en que el poder personal y las rivalidades entre escuelas o instituciones están subordinados a la investigación y a la demostración de la verdad; Jürgen Habermas, después de Adorno y Horkheimer, critica la dominación del pensamiento que él llama estratégico, aunque experimenta un horror absoluto por el recurso a las fuerzas populares (völkisch) que en Alemania condujo al nazismo. Pero, Habermas otorga al problema de la democracia moderna una amplitud mucho mayor. Posterior a Piaget, menciona que no hay democracia si no se escucha y reconoce al otro, si no se busca lo que tiene un valor universal en la expresión subjetiva de una preferencia y que la democracia es posible porque los conflictos sociales oponen a actores que si bien se combaten, se refieren a los mismos valores a los cuales tratan de dar formas sociales opuestas, esto es, que para que ésta exista, es preciso que los conflictos sociales estén limitados por valores como los de la modernidad, la racionalización y la subjetivación.

La democracia para muchos se define por la participación, pero para Alain Touraine, ésta se define por la libertad, por la creatividad de los individuos y los grupos así como por el nivel de las relaciones interpersonales. En pocas palabras, la democracia no es el triunfo del pueblo; es la subordinación del mundo de las obras, de las técnicas y de las instituciones, a la capacidad creadora y transformadora de los individuos y de las colectividades.

El autor de este libro nos lleva por todo este entramado de posibilidades, llegando a la conclusión de que la democracia es bastante nebulosa pero real; no significa el triunfo de lo uno ni la transformación del pueblo en príncipe, es "un horizonte utópico posible y realizable en la región”. Sin lugar a dudas, un libro que deberá ser leído por todos aquellos que aspiren a conocer cuál es esta parte de la realidad de nuestra América Latina.

Dr. AXel RAmírez

CEPE-UNAM 